\title{
E-learning and Distance Education: A Study of Iranian Teaching English as a Foreign Language Masters Students
}

\author{
Fatemeh Hemmati* and Hamid Mojarrad \\ University of Payame Noor, Tehran, Iran \\ *fatemehhemmati2002@yahoo.co.uk
}

Published online: 27 December 2016

To cite this article: Hemmati, F. and H. Mojarrad. 2016. E-learning and distance education: A study of Iranian Teaching English as a Foreign Language Master's students. Malaysian Journal of Distance Education 18(1): 53-70. http://dx.doi.org/10.21315/mjde2016.18.1.4

To link to this article: http://dx.doi.org/10.21315/mjde2016.18.1.4

\begin{abstract}
This study aimed at investigating the application of e-learning for master's students of Teaching English as a Foreign Language (TEFL) at Payame Noor University, the biggest distance education university in Iran and the Middle East. To do this, a questionnaire was sent to all students studying in five different Payame Noor centers around the country. After eliminating the incomplete questionnaires, 122 were analysed. Besides, 14 students as well as ten teachers were interviewed and 10 classes were observed to take advantage of a triangulated data collection method. The results revealed that distance learning students find some features of e-learning such as flexibility in time and class location very convincing; however, the status quo is not satisfactory due to shortcomings in areas including the Learning Management System (LMS) quality, web-based materials, and lack of interaction between students and teachers. Furthermore, despite their dissatisfaction, the students were happy to take e-learning courses because of their convenient features. Similarly, the teachers believed that e-learning can serve distance education, but many aspects such as teacher training courses, the number of students in each class, and the quality of under-web materials need to be improved. The results have some implications for using e-learning in distance education.
\end{abstract}

Keywords: E-learning, distance education, Learning Management System (LMS), Teaching English as a Foreign Language (TEFL) 


\section{Introduction}

The widespread use of information technology throughout the world has facilitated learning for different groups of people included the university students. The innovative thinking on the ways through which necessary skills and knowledge are acquired has led to new horizons. E-learning is considered to be the outcome of innovative transfer of knowledge and learning influenced vastly by the advent of the Internet and also Information and Communication Technologies (ICT) (Qureshi et al., 2012).

E-learning is considered a convenient and cost-effective mode of education for life-long learning. It has brought about several advantages compared with the traditional mode particularly in implementing 'learning anytime and anywhere' so that learners can access online course materials independent of time and place. Moreover, it allows students to work at their own pace, regardless of race, sex, disability, or appearance, and provides them with the opportunity to reflect on the learning materials and their responses (Richardson and Swan, 2003). Besides, e-learning has been reported (Nor Aniza and Lay Nee, 2015) to be more enjoyable, quicker, and easier than the traditional face-to-face tutorial.

In the recent decade, along with other universities in Iran, the Payame Noor University (PNU) has been trying to provide students with e-learning system and to implement it gradually for some levels of education including the master's degrees in order to further fulfill the university's slogan 'Education for everyone, everywhere, and every time'. Since 2006 when PNU has raised the matter and put it in the agenda, the number of students taking e-learning courses has increased and a larger number of $\mathrm{M}$. A. students have been accepted to study via this new mode of learning. The existing evidences indicate that the university is making considerable effort to reduce the limited number of traditional face-to-face courses and to replace them with e-learning ones.

Among the available academic disciplines, Teaching English as a Foreign Language (TEFL) is the subject area applied by many volunteers every year, and take the required courses in a virtual or electronic way, that is, e-learning. After several years of implementing e-learning in this field of 
study, it seemed necessary to make an evaluation on the merits and demerits of the present system from the viewpoint of teachers and students, because identifying factors affecting the students' satisfaction is of high importance to the university. The latest statistics show a drop in the number of students who study in distance education and although this is mainly due to a sharp fall in the number of young people in the population, the university authorities intend to eliminate factors that might deter students from applying and to foster those that help keeping students in the system.

\section{Review of Literature}

Students' perceptions and expectations regarding the use of e-learning system have been explored during the recent decades (e.g., Loh et al., 2016; Rhema and Miliszewska, 2014; Wang, 2004; Yaghoubi et al., 2008). There is a growing demand towards online learning as highlighted in the studies conducted by the National Center for Education Statistics (Waits and Lewis, 2003); however, as Anawati and Craig stated in 2006, the success of e-learning in distance education depends on many factors such as how easily students can access the web-based classes.

As one of the essential merits that e-learning might have over the traditional mode of learning, Petrides (2002) points out the collaborative working. He emphasises that the participants working in collaborative groups in an online course is much easier without needing to rearrange students' schedule as one might do in a face-to-face course. In addition, the ability to freely pick and choose from the menu of diverse learning experiences is another advantage of e-learning reported by the participants in the study carried out by Chizmar and Walbert (1999). Indeed, this advantage enables the participants to find the approaches that best fit the way they learn.

As for the potential demerits e-learning might bring about, Vonderwell (2003) highlights the lack of connection between students and instructor, especially at the time when they tend to have a sort of 'one-on-one' relationship with their teacher. Other studies found similar results. For example, according to the students who took part in the study carried out by Woods (2002), they felt isolated from faculty as well as their classmates in the online courses they experienced. 
From among the studies carried out on teachers' and instructors' attitude towards e-learning, a study was done by Tuparova et al. (2006) in Bulgarian universities. The findings indicated that instructors have definitely a positive attitude towards using computers and the Internet in their work. Positive attitude towards e-learning has been reported by other researchers too (e.g, Hossein, 2011; Psycharis, Chalatzoglidis and Kalogiannakis, 2013). On the other hand, there are reports indicating that e-learning is not popular among students or instructors for a number of reasons. For example, experiencing difficulties in technical issues, lack of familiarity with the system, and discussion overload were stated by students (Psycharis, Chalatzoglidis and Kalogiannakis, 2013). Moreover, lack of academic recognition and financial stimuli as well as the fact that preparation of e-materials is a time consuming activity were among the negative factors raised by instructors as sources of dissatisfaction with e-learning (Tuparova et al., 2006). By the same token, Behera (2012) investigated the attitude of college teachers towards e-learning and found that they neither agree nor disagree with the application of this mode of learning in the university.

At PNU, as mentioned before, during the last four years, a large number of MA students studying TEFL have registered in e-learning courses, but there has been no study to investigate different aspects of the system. Therefore, this study sought answers to the following research questions.

\section{Research Questions}

1. How do PNU students and teachers perceive the quality of LMS and the ease and usefulness of the e-learning system?

2. To what extent does the system maintain interaction and enhance the students' language skills?

3. How do the students and teachers evaluate the e-learning system for TEFL master's degree at PNU?

\section{Methodology}

\section{Participants}

The population of the study was the M. A. students of TEFL and their teachers at PNU who were involved in learning and teaching through the 
current e-learning system. Out of the 457 students studying master's degree in TEFL at PNU branches nationwide who received the questionnaires, 130 responded; however, only 107 students, including 76 females and 31 males were qualified to participate. Furthermore, 15 students participated in the interviews that were performed to elicit their ideas towards the running e-learning environment. As for the teachers, ten instructors out of the existing e-learning ones teaching at the PNU branches across the country were willing to take part in the interviews. It should be mentioned that due to the small number of teachers, they were not given questionnaires to fill in.

\section{Instruments}

The data of the study were collected utilising three instruments including questionnaire, observation, and interview. Below, they are elaborated on in more details.

\section{Questionnaire}

The questionnaire was designed and issued in a web-based format and in Persian, the native language of the participants. The web-based format was chosen to resemble the participants' mode of learning as they were e-learning students. It consisted of two main parts. The first part included some demographic information such as gender, age, students' entrance exam, and their familiarity with computers. Part two consisted of six categories and 40 items in total. The first category with seven items dealt with the usefulness of e-learning. The second category which included six items was concerned with interactivity in the system. The third one, consisted of five questions, was concerned with the strength of the system in enhancing students' language skills. The fourth section consisted of 11 questions on the portal quality. The fifth section consisted of five questions was concerned with teachers' roles. Finally, the last section which included five questions aimed at eliciting information about the students' evaluation of the system. The items were designed on a five-point Likert scale, ranging from strongly agree to strongly disagree.

The questionnaire was derived from different sources such as relevant research studies (e.g., Umrani-Khan and Iyer, 2009; Waheed and Hussain, 
2010; Mulwa and Kyalo, 2013), the researchers' own experience in teaching and studying at the same university, and finally, communication with students and teachers. These all created a good source of information to devise the inventory.

Initially, around 52 items were developed and given to six experts to comment on. Their suggestions led to some revisions and deletions. Thus, the items were tailored and boiled down to 40 items to be ready for a second judgment by five other experts. They were asked to judge the items for relevance, necessity, and usefulness. Thereby, the content validity of the items was taken care of. As for reliability, it was piloted with 36 students. The results yielded a Cronbach's alpha of 0.88 that indicates a high reliability coefficient.

\section{Observation}

In order to obtain more reliable results, the researchers made use of some observations in which ten sessions of TEFL classes were observed. It is noteworthy that the university records all the classes to provide students with further opportunity to use the classes in case they missed some. Therefore, the whole procedures of classes were available for observation.

\section{Interviews}

In addition to the quantitative method of collecting data from the participants through questionnaire, using interview as a qualitative method in parallel would lead to obtaining more reliable and closer to reality results. Hence, the study benefited from interviews not only for students but also for their teachers to investigate their ideas concerning the different aspects of e-learning system. That is, 15 students as well as ten teachers were interviewed.

\section{Procedure}

The process of data collection was done in two consecutive semesters in 2014. Having obtained the required reliability, the questionnaire's web page was broadly published and well-propagated on the university e-learning 
portal and the students were advised to take part in the survey. Meanwhile, the questionnaire's hyperlink was sent to the e-mails of a sizeable number of students whose addresses existed in the university's database to inform them about the study. The questionnaire was available and accessible on the web for two educational semesters for e-learning students. Besides, the questionnaire was printed out and handed to a number of students in person. Finally, 107 respondents completed the questionnaire including 76 female and 31 males.

With respect to the students' interviews, 15 volunteers of male and female students have been chosen to take part in a face-to-face interview. They were informed about the aims of the study and assured that the responses will be kept confidential and their participation will not affect their final marks.

As for the observations, by using the username and passwords provided by the LMS managers of the university, the researchers could attend the classes and observe the process of teaching the subjects. Besides, as mentioned before, the LMS provided all the students with recorded classes, so the classes were easily accessible to be observed at any time. Finally, a total of ten observations were carried out on ten subjects.

With regard to the teachers' interviews, ten instructors were briefed regarding the overall aim of the study. They were selected from among the teachers with at least two years of teaching experience in an e-learning environment. In the same way as the students, every teachers' interview was done in a separate occasion to allocate necessary time for addressing the case in details.

\section{Results and Discussion}

A one-sample $t$-test at 0.05 levels of significance was conducted to answer the research questions. Tables 1 and 2 illustrate the results of running $t$-test on the quality of LMS.

The output of the test shows that the sample (observed) mean (33.24) is slightly bigger than the population (theoretical) mean (test value $=33$ ). 
Likewise, the calculated $p$-value (0.721) is bigger than 0.05 (i.e. $p>0.05$ ). Hence, it indicates that the sample mean was statistically higher than the population normal mean, $t(106)=0.359, p=0.721$.

Table 1 Descriptive statistics for quality of LMS

\begin{tabular}{lcccc}
\hline \multicolumn{5}{c}{ One-Sample Statistics } \\
\hline$N$ & Mean & Std. deviation & Std. error mean \\
\hline Quality of LMS & 107 & 33.24 & 7.1 & 0.67 \\
\hline
\end{tabular}

Table 2 Findings of running one-sample $t$-test on quality of LMS

\begin{tabular}{lcccccc}
\hline \multicolumn{8}{c}{ One-Sample Test } \\
\hline & \multirow{8}{c}{$t$} & df & $\begin{array}{c}\text { Sig. } \\
(2-\text { tailed })\end{array}$ & $\begin{array}{c}\text { Mean } \\
\text { difference }\end{array}$ & $\begin{array}{c}95 \% \text { Confidence interval } \\
\text { of the difference }\end{array}$ \\
\cline { 2 - 7 } & & & & Lower & Upper \\
\hline Quality of LMS & 0.35 & 106 & 0.72 & 0.242 & -1.09 & 1.58 \\
\hline
\end{tabular}

To analyse the data more precisely, the scale was divided into five categories ranging from $1-1.8=$ strongly disagree, $1.8-2.6=$ disagree, $2.6-3.40=$ no comments, $3.40-4.20=$ agree and $4.20-5.00=$ strongly agree. In this way, dividing the observed mean by the number of questions yields the approximate mark for the whole category, that is, 3.02 in this case. This number is within the range of 2.6-3.4 (no comments); however, it does not mean that the majority of students did not want to comment on the items. It is rather the result of balance among the 11 questions of the category. For example, three items in this category which asked about overall agreement with the LMS quality were items number 19, 25, and 27. From among these, the highest agreement belongs to number 25 in which students showed satisfaction with recorded classes. The same point was emphasised on in the interviews as well. The absolute majority of students agreed that recorded classes are excellent opportunity in case they want to review the important points or when for any reason they miss a class. Besides, the notification section and the attractiveness of the homepage gained excellent marks. In the same category, items 23, 24, and 29 gained the highest disagreement, among them, number 24 which belongs to the video quality. Once more, in the interviews as well as the observations, it became obvious that many 
teachers turn the camera off and students do not see the teacher at all. Also, students were not happy with the audio quality (item 23) and the training they have received from the university to attend e-learning classes (item 29). Reporting technical and training problems is not limited to the context of the present study and have been reported by other researchers (e.g., Weller, Pegler and Mason, 2005; McGill and Hobbs, 2008 as cited in Psycharis, Chalatzoglidis and Kalogiannakis, 2013) as well; however, it is worth mentioning that in spite of lack of proper implementation, the students as well as their instructors have a positive attitude towards the system, a point which is in line with Hossein's (2011) study in which faculty members in Saudi Arabia showed positive attitudes towards e-learning despite of its deficiencies. The results were also in line with those of Stringer and Thomson, 1998 as well as Spiceland and Howkins, 2002. It seems that factors such as lack of free time to attend face-to-face classes, the expenditure of long trips, and family concerns which convince students to take e-learning classes are strong enough to keep them happy despite experiencing a lot of shortcomings.

To answer the second part of the first research question, the usefulness and ease of use category, Tables 3 and 4 depict the results of utilising $t$-test on the collected data.

Table 3 Descriptive statistics for usefulness and ease of use

\begin{tabular}{lcccc}
\hline \multicolumn{5}{c}{ One-Sample Statistics } \\
\hline & $N$ & Mean & Std. deviation & Std. error mean \\
\hline Usefulness and ease of use & 107 & 24.59 & 4.33 & 0.42 \\
\hline
\end{tabular}

Table 4 Findings of running one-sample $t$-test on usefulness and ease of use

One-Sample Test

\begin{tabular}{lcccccc}
\hline & \multicolumn{6}{c}{ Test Value $=21$} \\
\cline { 2 - 6 } & \multirow{2}{*}{$t$} & df & $\begin{array}{c}\text { Sig. } \\
\text { (2-tailed) }\end{array}$ & $\begin{array}{c}\text { Mean } \\
\text { difference }\end{array}$ & $\begin{array}{c}\text { 95\% Confidence interval } \\
\text { of the difference }\end{array}$ \\
\cline { 5 - 7 } $\begin{array}{l}\text { Usefulness and } \\
\text { ease of use }\end{array}$ & 8.58 & 106 & 0.000 & 3.59 & 2.76 & 4.42 \\
\hline
\end{tabular}


The findings show that the sample (observed) mean (24.59) is much bigger than the population (theoretical) mean (test value $=21$ ) and the calculated $p$-value $(0.000)$ is smaller than 0.05 (i.e. $p<0.05$ ) as well. Thus, it reveals that the sample mean was statistically significantly higher than the population normal mean, $t(106)=8.586, p=0.000$. Dividing the observed mean by the number of questions also yields the approximate mark for the whole category that is 3.51 in this case. This number sits within the range of 3.40-4.20 (agree) and proves that the students mostly agreed with these two advantages of e-learning.

Out of the 7 questions related to this category, three were concerned with the students' judgment about their ability to use the system and to learn how to work with it. The results showed the students' positive evaluations of their own abilities. In addition, there were other questions concerned with flexibility of class time, and the potentials of e-learning. The students evaluated the usefulness and ease of use of the LMS positively. These points were once more confirmed in the interviews. The interviewees believed that e-learning has all the potentials to be the best way to attend courses and that they were able to cope with learning how to use the system and catching up with modern technology. They also asserted that at the beginning they were very motivated and thought that they have found the best way to compromise between working, taking care of their families, and studying at the same time without leaving their families behind and taking frequent permissions from their workplaces to take part in face-to-face classes; however, the reality was totally different.

To answer the second research question, a one sample $t$-test was utilised for both interactivity and developing language skills which are further illustrated through the following tables.

Table 5 Descriptive statistics for interactivity

\begin{tabular}{ccccc}
\hline \multicolumn{5}{c}{ One-Sample Statistics } \\
\hline$N$ & Mean & Std. deviation & std. error mean \\
\hline Interactivity & 107 & 15.16 & 4.67 & 0.45 \\
\hline
\end{tabular}


Table 6 Findings of running one-sample $t$-test on interactivity

\begin{tabular}{lcccccc}
\hline \multicolumn{7}{c}{ One-Sample Test } \\
\hline & \multicolumn{7}{c}{ Test value $=18$} \\
\cline { 2 - 7 } & $t$ & df & $\begin{array}{c}\text { Sig. } \\
(2-\text {-tailed })\end{array}$ & $\begin{array}{c}\text { Mean } \\
\text { difference }\end{array}$ & $\begin{array}{c}95 \% \text { Confidence interval } \\
\text { of the difference }\end{array}$ \\
\hline Interactivity & -6.26 & 106 & 0.000 & -2.83 & Lower & Upper \\
\hline
\end{tabular}

The results represented a high gap between the population (theoretical) mean (test value $=18$ ) and the sample (observed) mean (15.17). Moreover, the calculated $p$-value $(0.000)$ was smaller than 0.05 (i.e. $p<0.05)$. Hence, it indicated that the sample mean was statistically significantly lower than the population normal mean, $t(106)=-6.268, p=0.000$. In addition, the approximate mark for the whole category after dividing the mean by the number of questions comes to 2.52 which stands within the range of 1.8-2.6 (disagree). This reveals that the majority of students disagreed with any considerable interactivity happening in the ongoing e-learning system.

With respect to the students' interviews, the absolute majority stated that there is only a one-way communication between teacher and students in their classes and the observations carried out on some of the courses supported the claim as well. Indeed, most of the class time was dedicated to the lesson based on the material specified by the university and there was no incentive remaining for the teachers to deal with students' other needs. As a result, the students feel isolated and ignored. These results were in line with those obtained by Vonderwell (2003) and Woods (2002) in which students felt isolated from the other students as well as faculty members. Similarly, Deb (2011) asserted that a feeling of isolation might result from the physical separation between instructors and students in e-learning environment. The attention students get from their instructors in electronic environment is closely related to their perception of feeling 'real' in this type of communication (Gunawardena and Zittle, 1997). It seems that in the present situation of e-learning at PNU, due to factors such as not having the opportunity to see their instructors and lack of proper interaction between instructors and students or among peers, there is no sense of social presence. 
As to the teachers' interview, most of them complained about the running e-learning LMS and the necessary facilities that the university should have provided for teachers to be able to have better communication with their students. Generally, they believed that a face-to-face teaching presently brings about much more room for teachers and students to interact with one another. Another point is that the large number of students, in some cases around 100, makes it very time consuming to try to communicate with students or even to reply to their e-mails.

Strictly speaking, the results of the questionnaire, the interviews as well as the observations indicated the virtual lack of interaction. It seems that the lack of communication and interaction is the most damaging inadequacy in the system. While many researchers believe that no learning takes place without interaction, it seems that interaction has been completely neglected in the present LMS at PNU. Lack of interaction can have other consequences such as lack of feedback from the students to the teacher and vice versa. This point was emphasised on by all the teachers that due to lack of feedback from the students, teachers have to talk all the time leading to tiredness and fatigue. Interaction is influential in all types of learning, but it is more crucial when the subject is concerned with teaching a foreign language.

The following tables display the results of implementing one-sample $t$-test on the data collected on Developing Language Skills questions.

Table 7 Descriptive statistics for developing language skills

\begin{tabular}{lcccc}
\hline \multicolumn{5}{c}{ One-Sample Statistics } \\
\hline & $N$ & Mean & Std. deviation & Std. error mean \\
\hline Developing language skills & 107 & 13.38 & 4.80 & 0.46 \\
\hline
\end{tabular}

Table 8 Findings of running one-sample $t$-test on developing language skills

\begin{tabular}{lcccccc}
\hline \multicolumn{6}{c}{ One-Sample Test } \\
\hline & \multirow{6}{c}{\begin{tabular}{c} 
Test Value $=15$ \\
\hline
\end{tabular}} & df & $\begin{array}{c}\text { Sig. } \\
(2-\text { tailed })\end{array}$ & $\begin{array}{c}\text { Mean } \\
\text { difference }\end{array}$ & $\begin{array}{c}\text { 95\% Confidence interval } \\
\text { of the difference }\end{array}$ \\
\cline { 2 - 7 } & & & Lower & Upper \\
\hline $\begin{array}{l}\text { Developing language } \\
\text { skills }\end{array}$ & -3.48 & 106 & 0.001 & -1.61 & -2.53 & -0.69 \\
\hline
\end{tabular}


The findings indicate a relatively high difference between the population (theoretical) mean (test value $=15$ ) and the sample (observed) mean (13.38). Furthermore, the calculated $p$-value (0.001) is smaller than 0.05 (i.e. $p<0.05)$. Therefore, it reveals that the sample mean was statistically significantly lower than the population normal mean, $t(106)=-3.481$, $p=0.001$. Besides, the estimated mark for the whole category after dividing by the number of questions equals to 2.67, that is, within the range of 2.63.40 (no comments) and closer to the beginning of the range (2.6) which is the end point of disagree interval. Therefore, the students tended to disagree with the level of development occurring in language skills.

The students' interviews also showed that there is a growing concern on their English proficiency as they were not satisfied with the process of this development. A significant number of students believed that the matter of language skills development is not defined among the specified objectives of the course; as a result, teachers only concentrate on the material in question. As there is no substantial interaction between teachers and students, no noticeable development occurs in language skills such as speaking. Observations represented the same results and confirmed that the matter of developing language skills is not on the teachers' agenda at all and the class goes only on some explanations about the lessons.

Likewise, the teachers were asked whether they have any plan for enhancing the students' language skills. They believed that the students' language skills should have already been developed over the past years prior to their admission to master's studies. Hence, the teachers not only had no idea or intention to conduct the class in a way that leads to developing the students' language skills, but also didn't believe in the necessity of allocating a portion of class hours for this purpose.

Regarding the last research question, the same test method was employed to analyse the data. The results are depicted in more details in the following tables. 
Table 9 Descriptive statistics for students' consensus and evaluation

\begin{tabular}{lcccc}
\hline \multicolumn{5}{c}{ One-Sample Statistics } \\
\hline & $N$ & Mean & Std. deviation & Std. error mean \\
\hline Consensus and evaluation & 107 & 15.06 & 5.55 & 0.53 \\
\hline
\end{tabular}

Table 10 Findings of running one-sample $t$-test on students' consensus and evaluation

\begin{tabular}{lcccccc}
\hline \multicolumn{7}{c}{ One-Sample Test } \\
\hline & $t$ & df & $\begin{array}{c}\text { Sig. } \\
(2 \text {-tailed) }\end{array}$ & $\begin{array}{c}\text { Mean } \\
\text { difference }\end{array}$ & $\begin{array}{c}\text { 95\% Confidence interval } \\
\text { of the difference }\end{array}$ \\
\cline { 2 - 7 } & 0.122 & 106 & 0.90 & 0.065 & -0.99 & 1.13 \\
\hline $\begin{array}{l}\text { Consensus and } \\
\text { evaluation }\end{array}$ & & & & & & Upper \\
\hline
\end{tabular}

The results highlighted a relatively same value for both the population (theoretical) mean (test value $=15$ ) and the sample (observed) mean (15.06). The calculated $p$-value (0.903) is bigger than 0.05 (i.e. $p>0.05$ ) too. Moreover, the approximate mark for the whole category equals to 3.01 which stands within the range of 2.6-3.40 (no comments). It seems that the students have shown a lot of hesitation when asked about the future of e-learning for master's degree in TEFL, its being a good substitute for face-to-face classes and to choose between the two types of learning. For example, when asked if they find e-learning classes more attractive because they are done through modern technology, around $60 \%$ of students either disagreed or preferred not to comment on the item. The same was true about the item which asked them about their preference if they were to choose between the two types of learning. Once more the majority either disagreed or did not comment on the item. However, in response to another question which asked them whether they are happy with their decision for taking e-learning classes, around 50\% asserted that they are and a rather large number (23 students) did not comment on the items. In response to the same questions in the interviews they emphasised that due to their family and work commitments they are still happy with their decision to take e-learning classes, although the reality is not what they imagined. Furthermore, in item number 40, students found that the electronic learning 
is more modern, appealing, and attractive; however, items of number 30 , 31 , and 35 were given very low marks for the amount of attention they get from their teachers, the clear aim of the lesson stated by the teacher, and the student centeredness of classes.

Another point mentioned by almost all the interviewees was the fact that not every M. A. center of the University for TEFL is currently responsive to its own e-learning students. In other words, presently at PNU there are five centers which recruit M. A. students in TEFL; however, for the e-learning students, there is only one center in charge of holding the classes and being responsive to the students all over the country. In fact, students might be accepted by Tehran center, but since Tehran is not the responsible center for e-learning students they end up with a lot of confusion and dissatisfaction.

Teachers, in the same way, were complaining about the e-learning system during the interviews. They stressed that the system should prepare the ground for further communication with the students and provide the instructors with the required facilities to allocate more time for presenting the material in a way that leads to a better achievement for the students and also meets their educational needs. They also emphasised that the university has taken the initial steps to establishing the e-learning system, but many aspects such as proper teacher training programs, web-based contents, and improving the LMS quality remain to be done.

\section{Conclusions and Implications}

Based on the findings of the study, it can be concluded that e-learning at PNU is considered an excellent way to overcome the problems such as attending face-to-face classes in far cities which necessitates costly journeys as well as leaving families and works behind. However, technical problems such as video and audio quality, download speed, and lack of communication with instructors or peers cause a lot of despair and apathy.

Despite all the drawbacks in the system, it seems both students and teachers still believe that e-learning can potentially be a good substitute for traditional face-to-face learning; therefore, the PNU authorities who are insisting on the motto of 'education for everyone, everywhere, and every time' need to reconsider the facilities and the vast opportunities that e-learning can offer. 
Being a popular field of study in Iran, Teaching English as a Foreign Language is one of those fields that require to be taught and learned in an interactive environment. TEFL students should be constantly developing their English language skills as they are supposed to be the future English teachers and consequently should identify and resolve any shortcomings or defects they might have in language skills. Considering the results of the study, there is a need for the provision of appropriate web-based material and the development of expertise in e-learning use both for students and teachers. Furthermore, equipping the system with more facilities and reducing the number of students in each class are important tasks that necessitate substantial attention from the authorities.

Along with the necessity of fostering the LMS with facilities for teacherlearner and learner-learner interaction, the university authorities need to pay specific attention to the requirements of different fields of study as well as the development of expertise in e-learning. Other areas of research related to the same topic such as the successfulness of the two systems in helping students to pass the courses are areas that remain to be explored in further studies.

\section{Acknowledgement}

This work was supported by University of Payame Noor Iran, Tehran.

\section{References}

Anawati, D. and A. Craig. 2006. Behavioral adaptation within cross-cultural virtual teams. IEEE Transactions on Professional Communication 49: 44-56. https://doi. org/10.1109/TPC.2006.870459

Behera, S. K. 2012. An investigation into the attitude of college teachers towards e-learning in Purulia district of West Bengal India. Turkish Online Journal of Distance Education 13(3): 152-160.

Chizmar, J. F. and M. S. Walbert. 1999. Web-based learning environments guided by principles of good teaching practice. Journal of Economic Education 30(3): 248264. https://doi.org/10.2307/1183061

Deb, S. 2011. Effective long distance learning in developing countries using mobile and multimedia technology. International Journal of Multimedia and Ubiquitous Engineering 6(2): 33-40. 
Gunawardena, C. and F. Zittle. 1997. Social presence as a predictor of satisfaction within a computer-mediated conferencing environment. American Journal of Distance Education 11: 8-26. https://doi.org/10.1080/08923649709526970

Hossein, H. B. 2011. Attitudes of Saudi universities faculty members towards using learning management system (JUSUR). The Turkish Online Journal of Educational Technology 10(2): 43-53.

Loh, C. D., H. Wong, A. Quazi and R. P. Kingshott. 2016. Re-examining students' perception of e-learning: an Australian perspective. International Journal of Educational Management, 30(1): 129-139. https://doi.org/10.1108/ijem-08-2014-0114

Mulwa, A. S. and D. N. Kyalo. 2013. The influence of principals', teachers', and students' attitude on readiness to adopt e-learning in secondary schools in Kitui district, Kenya. European Scientific Journal 9(5): 183-202.

Nor Aniza, A. and Ch. Lay Nee. 2015. Technology and higher education: Using an E-learning tutorial as a pedagogy for innovation and flexible learning. Malaysian Journal of Distance Education 17 (1): 21-31.

Petrides, L.A. 2002. Web-based technologies for distributed (or distance) learning: Creating learning-centered educational experiences in the higher education classroom. International Journal of Instructional Media 29(1): 69-77.

Psycharis, S., G. Chalatzoglidis and M. Kalogiannakis. 2013. Moodle as a learning environment in promoting conceptual understanding for secondary school students. Eurasia Journal of Mathematics, Science \& Technology Education 9(1): $11-21$.

Qureshi, A., K. Ilyas, R. Yasmin and M. Whitty. 2012. Challenges of implementing e-learning in a Pakistani university. Knowledge Management \& E-Learning: An International Journal 4(3): 310-324.

Rhema, A. and I. Miliszewska. 2014. Analysis of student attitudes towards e-learning: The case of engineering students in Libya. Issues in Informing Science and Information Technology 11: 169-190. http://iisit.org/Vol11/IISITv11p169-190Rhema0471.pdf

Richardson, C. J. and K. Swan. 2003. Examining social presence in online courses in relation to students' perceived learning and satisfaction. Journal of Asynchronous Learning Networks, 7(1): 68-84.

Spiceland, J. D. and P. C. Hawkins. 2002. The impact on learning of an asynchronous active learning course format. Journal of Asynchronous Learning Networks 6(1): 68-75.

Stringer, S. B. and J. S. Thomson. 1998. Evaluating for distance learning: Feedback from students and faculty, 2-7. ERIC Document Reproduction Service No. ED422879

Tuparova, D., G. Tuparov, S. Ivanov, E. Karastranova and J. Pevena. 2006. Teachers' attitude towards e-learning courses in Bulgarian universities. Current Developments in Technology-Assisted Education. http://www.formatex.org/micte2006/pdf/17551759.pdf.

Umrani-Khan, F. and S. Iyer. 2009. ELAM: A model for acceptance and use of e-learning by teachers and students. International Conference on e-learning (ICEL), Toronto, Canada, July 2009. 
Vonderwell, S. 2003. An examination of asynchronous communication experiences and perspectives of students in an online course: A case study. Internet and Higher Education 6: 77-90. https://doi.org/10.1016/S1096-7516(02)00164-1

Waheed, M. and M. F. Hussain. 2010. Conference Paper: Empirical study of learner contentment towards eLearning: Influential Role of key factors in International. Learning International Networks Consortium, LINC, Massachusetts, USA; $01 / 2010$.

Waits, T. and L. Lewis. 2003. Distance education at degree-granting postsecondary institutions: 2000-2001 (NCES 2003-017). U.S. Department of Education, National Center for Education Statistics. http://nces.ed.gov/pubsearch/ pubsinfo. asp?pubid=2003017 (accessed 8 January 2005).

Wang, Y. S. 2004. Assessment of learner satisfaction with asynchronous electronic learning systems. Information \& Management 41: 75-86. https://doi.org/10.1016/S03787206(03)00028-4

Woods, R. H. 2002. How much communication is enough in online courses? Exploring the relationship between frequency of instructor-initiated personal email and learners' perceptions of and participation in online learning. International Journal of Instructional Media 29(4): 377-394.

Yaghoubi, J., I. Malek Mohammadi, M. Attaran, H. Iravani and A. Geidi. 2008. Virtual students' perception of e-learning in Iran. The Turkish Online Journal of Educational Technology 7(3): 89-95. 